\title{
EL AGUA SUBTERRÁNEA EN LOS BAJOS SUBMERIDIONALES SANTAFESINOS Y SU APROVECHAMIENTO EN LA PRODUCCION GANADERA
}

\author{
SosA, D. ${ }^{1}$
}

\begin{abstract}
RESUMEN
Se describe el funcionamiento de los flujos subterráneos en una gran llanura sedimentaria de miles de metros de espesor. Las aguas superficiales, como subterráneas presentan, generalmente, altos contenidos salinos. Al este, el colector natural de estas aguas es el Arroyo Golondrinas. La topografía presenta suave pendiente hacia el sureste con lagunas permanentes y semipermanentes. La circulación de flujos subterráneos explica la complejidad química como el resultado de relaciones entre flujos locales que interactúan con flujos intermedios y profundos. En su mayoría las aguas subterráneas se clasifican como sulfatadas, cloruradas y sulfatadas-cloruradas sódicas. Las aguas con menores concentraciones salinas se ubican en bolsones y paleocauces que pueden aumentar su calidad con obras de recarga a partir de pozos con filtro horizontal. Los excelentes resultados obtenidos con estas obras las hacen recomendables para mejorar las aguadas en una región donde la principal actividad productiva es la ganadería de cría.
\end{abstract}

Palabras clave: flujos subterráneos, bajos submeridionales, recarga artificial, paleocauces.

\begin{abstract}
Underground water in the submeridional lowlands of Santa Fe and its exploitation for livestock production.

Functioning of the groundwater flow is described in a sedimentary plain with a thickness of thousands of meters. Surface water, and groundwater have generally high salt content. To the East, the natural discharge of these waters is Golondrinas Creek. The topography presents a gentle slope to the southeast with permanent and semi-permanent ponds. Circulation of groundwater flows and chemical complexity are explained as the result of relations between local flows that interact, with
\end{abstract}

1.-INA CRL Instituto NAcioanl Centro Regional Litoral. Email: sosa.dora@gmail.com

Manuscrito recibido el 8 de septiembre de 2016 y aceptado para su publicación el 2 de diciembre de 2016. 
intermediate and deep flows. Most groundwater is classified as sulphate, chloride and sodium chloride-sulphate. Waters with lower salt concentrations are located in depression and paleochannels, and can be further improved their quality and quantity, through artificial recharge pumping from horizontal collector wells. The excellent results of these works make them desirable to improve watering place in a region where the main productive activity is livestock breeding.

Key words: groundwater flow, Bajos Submeridionales, artificial recharge, paleochannel.

\section{INTRODUCCION}

Como Bajos Submeridionales (BBSS) se denomina a una extensa región de aproximadamente $54.280 \mathrm{~km} 2$ situada en el centro norte del país, dentro del Chaco argentino (Figura 1), que en el mapa de cuencas hídricas realizado por la Subsecretaría de Recursos Hídricos de la Nación (SRHN) se la identifica como cuenca $\mathrm{N}^{\circ} 22$. Esta región se extiende en tres provincias argentinas: Santiago del Estero (24.95 \%), Chaco $(23.57 \%)$ y noroeste de la provincia de Santa Fe (51.38\%) (Figura 2 (a y b)). En esta última provincia, donde tiene su mayor extensión, dicha región limita al Este con la Cuña Boscosa junto a la cañada y arroyo Golondrinas y al Oeste con la Ruta interprovincial $\mathrm{N}^{\circ} 35$, que marca la separación del Dorso Occidental Sub-húmedo ingresando ya en territorio santiagueño. El límite Sur está marcado por el Río Salado. Hacia el Norte, ingresa en la provincia de Chaco donde se plantea un límite ondulado que abarca masas forestales del Bosque de la Viruela y Gato Colorado, los cuales pueden asimilarse a la Cuña Boscosa y al Dorso Occidental Sub-húmedo, respectivamente (15). La principal actividad productiva corresponde a la ganadería de cría, aunque en años húmedos, aún en tierras con baja a deficiente capacidad producti- va agrícola, muchas de ellas se destinan a la agricultura. Estas actividades están muy condicionadas a la disponibilidad de agua de la región.

Las diferencias encontradas entre los límites definidos por la SRHN para esta región de estudio (cuenca $\mathrm{N}^{\circ} 22$ ) y los considerados por la provincia de Santa $\mathrm{Fe} \mathrm{y} \mathrm{otros}$ trabajos realizados por el Instituto Nacional del Agua (INA) se presentan en la (Figura 3 (a y b)) (18).

Tanto las aguas superficiales como las subterráneas presentan, en general, altos contenidos salinos. El colector natural de las aguas es el Arroyo Golondrinas, que a su vez descarga en el río Calchaquí, tributario del río Salado (8) definieron a la zona de estudio, por el comportamiento de las aguas superficiales, como un sistema hidrológico de características no típicas, donde prevalecen los flujos laminares. Además, como consecuencia de las precipitaciones, las tenues elevaciones que separan las depresiones pueden ser traspuestas por importantes volúmenes de agua en forma de manto, en uno u otro sentido.

La acumulación de agua en las depresiones naturales forma las grandes reservas de biodiversidad, mientras que la escasez de vegetación arbórea es ocupada por densos espartillares de Spartina argentinensis que se encuentran en las tres cuartas partes 